\title{
MOTIVATION INFLUENCING WORKER PERFORMANCE IN A TECHNICAL DIVISION OF TELKOM SA
}

\author{
TFJ OOSTHUIZEN (RAU)
}

This paper investigates the overall motivational level of employees in a technical division of Telkom SA during change periods. Specific reasons for the established levels of motivation are identified. Based on the six motivator factors and ten hygiene factors as presented by Herzberg, it is the conclusion of this study that the solution to motivate employees are based on informed and positively motivated employees who participate continuously in the change process at all levels.

\section{INTRODUCTION}

Since the beginning of the previous century, employers and social scientists have started looking at the role that work fulfils in satisfying man's needs and in the utilisation and development of his abilities. Emphasis has been placed primarily on the psychological and sociological aspects of work. Management has been interested in these developments primarily for increasing productivity. From this research into man's needs, a number of theories have evolved relating to work motivation.

In today's competitive world and market it is essential that an organisation have positively motivated employees to improve productivity and efficiency. All too often motivation and performance are assumed to be one and the same. This faulty assumption can lead to poor managerial decisions. Motivation is one of the factors that directly influence performance. Others include level of ability, level of skill, knowledge about how to complete the task, as well as inhibiting conditions not under the individual's control (Kreitner \& Kinicki 1989:150).

Performance $=$ Motivation $\times$ Ability $\times$ Skill $\times$ resources

\section{BACKGROUND}

Telkom SA is one of the South African organisations that have been exposed to a changing external business environment. This resulted in internal change reaction to accommodate the changing forces within their own organisational functioning, specifically with reference to the South African industry. For Telkom SA to become internationally competitive and world-class it will have to look, among other things at its human resources. The attitude and motivational level of all employees towards this objective is a critical success factor.

Telkom used to be a government department and formed part of the Department of Post and Telecommunication. It was commercialised on 1 October 1991. It remained a wholly stated-owned enterprise until May 1997. A thirty percent equity stake was sold to a strategic equity partner, the consortium of SBC Communications International and Telkom Malaysia (Telkom 2000a: Internet).

With the government as majority shareholder, Telkom has a social responsibility to extend the telecommunications network to reach more people in areas where a shortage of telecommunication infrastructure exists. Secondly, Telkom must modernise its network in the so-called serviced areas by phasing out older equipment and be able to provide new telecommunication services to corporate customers who demand a first world network with advanced services.

Telkom SA currently has the monopoly, being the only national fixed national telecommunications network operator, in providing fixed line telephony in terms of its licence to provide public switched telecommunication services (PSTS). The licence for Telkom SA to exclusively provide PSTS will expire in 2002. This will the open the door to other operators to provide public switched telecommunication services in direct competition with Telkom (Telkom 2000a: Internet).

Telkom SA is undergoing major changes of which the biggest change resulted in organisational culture change from state parastatal to a private company. Telkom SA is in the process of moving from a second wave management style to a third wave management approach. This has led to 
feelings of uncertainty among the work force mainly due to ignorance, misunderstanding, fear of economic loss as well as fear of the unknown. Telkom SA faces a challenge, since it only has a limited period of time in which it will be the sole telecommunications provider in South Africa. Once this exclusivity has expired, it will have to face full global competition. To meet this challenge, the company will need, among other things, highly positive motivated employees.

The ability of the organisation to succeed in realising their vision, excellent service based on worldclass communications performance is of essence (Telkom 2000b: Internet). The organisation success is further based on the excellence of the technical divisions within the greater organisation. Synergy can only be established if all entities within an organisation function within the shared vision.

If research on motivation is based on a well-defined focus area within an organisation, the results achieved cannot be assumed to be representative of the total organisation. This also does not implicate that the outcome of such research does not have any or minimal influence on the greater organisation. The implication in the Telkom scenario is that research outcomes on a specific division identify possible success and problem areas that must be investigated and analysed in other divisions within Telkom. This continuous analysis will enable management to establish core factors relating to Telkom as well as unique factors with reference to the various divisions within Telkom, which have a major impact on the motivation of personnel and therefore their performance.

\section{MOTIVATIONAL THEORIES}

Various motivational theories sighted mostly in textbooks on organisational behaviour and general management has certain strengths and limitations indicating no clear-cut superiority over another. Motivation focuses on influences, which create, direct, and sustain, goal directed behaviour.

Managers must motivate a diverse and in many respects an unpredictable group of people. This diversity results in different behavioural patterns that are related to goals and needs.

Motivational theories can broadly be divided in two categories when focusing on behaviour of individuals. Content theories explore the factors that influence behaviour. Process theories on the other hand analyse how people behave.

Four content theories, most frequently found in literature, include Maslow's need hierarchy, Alderfer's ERG theory, Hertzberg's two-factor theory and McClelland's learned needs theory. Process theories include Vroom's expectancy theory, Porter-Lawler expectancy model, Adams' equity theory, Locke's goal setting theory and Skinner's reinforcement theory. There are numerous other motivation theories but this research focus on the above-mentioned due to their relevance to the organisation and specifically management.

\section{Content theories}

Content theories emphasise the needs that motivate people. These needs translate into internal drives that give rise to specific behaviour intended to fulfil these needs (Hellriegel \& Slocum 1996: 412). The various theories can be compared according to identified levels of needs. Needs can be grouped as lower level needs and higher level needs. The summarised diagram 1 below indicates the relationships and differences between the four identified theories.

Diagram 1 focuses more on the positive relatedness that exists between the various theorists and not to establish exact similarities.

- Maslow's needs hierarchy served as the basis for the ERG model, therefore the similarities. The major difference is that Maslow's need hierarchy is a static system based on the fulfilmentprogression, whereas the ERG theory presents a flexible three-needs system based on a frustration-progression process.

- Hertzberg's theory draws on both the needs models. That is, if hygiene factors are present, the physiological and security needs are likely to be met. Motivator factors focus on the job itself and the opportunity for a person to satisfy higher order needs or growth needs. 
- McClelland's model does not recognise lower order needs. The need for affiliation corresponds with level 3 of Maslow's need hierarchy. McClelland's need for achievement correlates with the motivators of Herzberg (Menyennett 1999: 22). Finally the need for power has no direct correlation with specific need levels in comparison to other theorists but it is recognised as a high level need.

\section{Diagram 1 A comparison of content theories}

\begin{tabular}{|c|c|c|c|c|c|}
\hline \multirow[t]{2}{*}{ Levels } & \multirow{2}{*}{ Need level } & \multicolumn{4}{|c|}{ Theories } \\
\hline & & $\begin{array}{c}\text { Maslow } \\
\text { Needs hierarchy }\end{array}$ & $\begin{array}{l}\text { Herzberg } \\
\text { Two-factor }\end{array}$ & $\begin{array}{c}\text { Alderfer } \\
\text { ERG }\end{array}$ & $\begin{array}{l}\text { McClelland } \\
\text { Learned needs }\end{array}$ \\
\hline 5 & \multirow{3}{*}{ High } & $\begin{array}{l}\text { Self-actualisation } \\
\text { needs }\end{array}$ & \multirow{3}{*}{$\begin{array}{l}\text { Motivator } \\
\text { factors }\end{array}$} & \multirow{3}{*}{ Growth need } & \multirow{3}{*}{$\begin{array}{l}\text { Need for: } \\
\text { Power, } \\
\text { Achievement, } \\
\text { Affiliation }\end{array}$} \\
\hline & & & & & \\
\hline 4 & & $\begin{array}{l}\text { Esteem } \\
\text { Needs }\end{array}$ & & & \\
\hline 3 & \multirow{3}{*}{ Low } & $\begin{array}{l}\text { Social } \\
\text { Needs }\end{array}$ & \multirow{3}{*}{$\begin{array}{l}\text { Hygiene } \\
\text { factors }\end{array}$} & $\begin{array}{l}\text { Relatedness } \\
\text { need }\end{array}$ & \\
\hline 2 & & $\begin{array}{l}\text { Safety \& security } \\
\text { needs }\end{array}$ & & \multirow[t]{2}{*}{ Existence need } & \\
\hline 1 & & $\begin{array}{l}\text { Physiological } \\
\text { needs }\end{array}$ & & & \\
\hline
\end{tabular}

\section{Process theories}

Content theories revolve around needs and related factors that energise behaviour. Process theories what channels behaviour toward goals and how people choose to behave as they do (Mescon et al. 1988: 397). Need theories view motivation as subconscious and instinctive? Process theories view motivation in terms of the explicit thought processes (cognitions) and conscious decisions to select and pursue a specific choice, of employees (Ivancevich et al. 1994: 369). Last mentioned group of theories does not dispute the existence of needs, but contend that behaviour is not solely a function of needs. 
Each of the process theories has a specific orientation. Vroom's expectancy theory is concerned with the expectations of a person and how they will influence behaviour. Employees choose among alternative behaviours according to their expectation that a particular behaviour will lead to a desired outcome. If satisfactory performance will result in a desired outcome, which the employee values highly, then the employee will be motivated to improve performance.

The Porter-Lawler model is an extension of the expectancy theory and suggests that performance lead to satisfaction. Motivation is a function of needs, expectancies and perceived equity. Performance is dependant on an individual's effort, abilities, traits and the individual's perception of his/her role. The theory establishes a relationship between rewards and performance, namely that an individual satisfies needs through rewards received because of performance. According to Porter and Lawler, performance leads to satisfaction, not vice versa, as the many human relations' schools tended to believe.

Adams' equity theory primarily addresses the relationship between attitudes toward inputs and outcomes and toward reward practices. It suggests that people subjectively determine the ratio of reward to effort (outcomes to inputs) and compare it to what they perceive others to receive for similar effort. Generally, effort will decrease if the person feels under rewarded and remain unchanged or increase if the person feels over rewarded.

Goal-setting, as proposed by Locke, emphasises that cognitive processes and the role of conscious goals and intentions as primary determinants of behaviour. Setting a goal that is specific and challenging leads to an increase in performance, because it makes it clearer to individuals what they are supposed to do. Generally, the more difficult the goal, the higher the level of performance.

The reinforcement theory focuses on the work environment, virtually ignoring the notion of individual needs and attitudes. It focuses on the wise application of rewards and punishment to encourage or inhibit behaviour. Skinner's reinforcement model suggests that behaviour is a function of its consequences (rewards or punishment). Behaviour that is rewarded is likely to be repeated. Undesired behaviour that is punished is likely to cease.

Each process theory has a very specific orientation and is therefor very difficult to compare. Each theory takes a different approach to the exact process that results in specific behaviour.

\section{APPLICATION OF THE MOTIVATOR-HYGIENE THEORY}

Organisations that require workers that perform routine tasks have been plagued with problems of high turnover, absenteeism, grievances, low productivity and so on. These firms generally relied on hygiene factors to motivate their employees (Hellriegel \& Slocum 1996:420). However, while hygiene factors can reduce job satisfaction, they do not improve performance. According to Herzberg, management should turn to motivators to solve this problem.

As previously mentioned, two separate factors associated with job satisfaction and dissatisfaction, were identified by Herzberg. There are six factors related to job content - called the motivators - that, when present, build strong levels of motivation. The second set of ten factors, called the hygiene factors, refers to the job context. The presence of these factors does not necessarily motivate the employee, but their absence results in dissatisfaction.

\section{Motivators}

The six motivators are as follows (Herzberg 1968:95):

- Achievement: Achievement refers to the reach or attainment of something through effort, the successful accomplishment or completion of a task, the solving of a problem, the maintaining of a position and lastly the visible results of a person's work.

- Recognition: To acknowledge the contribution of a person, to express appreciation or to reward the individual for the accomplishment of the task. 
- Responsibility: Giving the person the liability, accountability and answerability for a task or person.

- Advancement: The promotion of an individual.

- The work itself: The doing of the work and the type of work. The job can be repetitive or changing, creative or monotonous, easy or difficult.

- The possibility of growth: An individual can grow in experience, skills, knowledge, status and seniority.

\section{Hygiene factors}

The ten hygiene factors are as follows (Herzberg 1968:95):

- Salary: It includes all financial rewards, such as the actual salary, salary increase, performance increase etceteras.

- Supervision: It includes all the skills and abilities of the supervisor to lead, to coach and to solve problems. These aspects are crucial for his/her success.

- Relationship with supervisor: A good relationship with the supervisor resulting in continuous learning, willingness to listen to subordinate proposals, willingness to give credit and to defend the employee.

- Relationship with subordinates: Positive interpersonal relationships based on subordinate's support and acceptance. In return subordinates expect opportunities, leading, coaching and support from the supervisor.

- Relationship with fellow workers: A pleasant relationship is present when a person likes fellow workers, get their support and act together as a strong team.

- Company policy and procedures: This includes human resources policy, work organisation, production and other facilities, procedures and non-financial privileges.

- Physical working conditions: The pertains to the quantity of work, availability of resources such as machinery and tools, and physical working environment such as ventilation, lighting, work space and air conditioning.

- Factors in the worker's personal life: Long working hours and high stress can influence a person's personal life resulting in him/her having negative feelings toward the job.

- Status: This includes status symbols like position title, office size, company car, type and size of office furniture.

- Job security: Factors that lead to a feeling of job security includes the survivability of the organisation, the safety of a person's specific job/position, a medical aid and pension fund.

\section{RESEARCH METHODOLOGY}

The structure of the research is based on the six motivator factors and ten hygiene factors as presented by Herzberg. The study focuses on the motivational level of employees in a technical division of Telkom SA. The division, known as Switching Engineering, consists of 168 people of whom 20 are first level managers and the rest comprises of supervisors and non-managerial employees. The division is divided into six geographical areas: North Eastern, Gauteng Central, Eastern, Central, 
Southern and Western region. The division is responsible for the planning of electronic equipment for all the telephone exchanges (2630 in total) in South Africa (Menyennett 1999:61).

\section{CONCLUSIONS}

\section{Conclusion on primary objective}

The primary objective is to investigate the overall motivational level of the suggested target group and to identify possible reasons for the established levels of motivation. The results indicate an average overall motivational level in this division. This is in contrast to the low levels encountered when the research proposal was compiled in 1998. Since then changes and employee turnover have been a regular phenomena. The factors: achievement, the work itself as well as responsibility, contributed significantly to stronger levels of motivation. On the other hand the factors advancement, and the possibility of growth contributed to levels of dissatisfaction.

The hygiene factors: interpersonal relationships, supervision and working conditions produced strong levels of satisfaction. Thus a good working relationship exists between supervisors and employees as well as between co-workers. The hygiene factors that contributed predominantly to dissatisfaction were company policy and procedures, salary, status, job security as well as factors influencing employees' personal lives.

Motivators contributed fifty two point seven percent and hygiene factors fourty seven point four percent of responses for satisfaction. Hygiene factors contributed to sixty seven point six percent and motivators to thirty two point four percent of dissatisfaction. According to the Motivator-hygiene theory, the absence of hygiene factors is leading to these levels of dissatisfaction. Furthermore is the absence of motivators leading to a situation of "no satisfaction", where the presence of motivators is suppose to build strong levels of motivation.

\section{Conclusion on secondary objectives}

Taking into account the primary objective of overall motivational levels in the division, various secondary objectives are also prevalent when analysing motivation in the suggested target group. The secondary objectives include:

- To compare the level of motivation between the six different regions;

- To investigate the level of motivation of the first level managers;

- To investigate the level of motivation of the employees reporting to these managers;

- To establish a motivational profile based on significant differences between regions as well as managers/employees;

- To make suggestions and recommendations to middle management regarding motivation and possible methods of improving motivation.

Comparing the regions, it is evident that they are quite similar. Taking all the regions into account, motivators contribute between fifty point twp percent and fifty four point seven percent and hygiene factors between forty five point three percent and forty nine point eight percent, to satisfaction. Motivators represent between twenty eight point two percent and thirty four point four percent to dissatisfaction, whereas hygiene factors contribute between sixty five point six percent and seventy one point eight percent. In all regions the factors achievement, recognition, the work itself and responsibility contributed to the good level of motivation. Interpersonal relationships and in some regions, supervision, also contributed to the high level of satisfaction. This emphasises that there is good teamwork amongst co-workers and employees and supervisors. Except for the Eastern region the two factors acting as strong dissatifiers, are advancement and company policy and procedures. Other factors that also contribute to dissatisfaction, varying from region to region, include salary, status, job security as well as factors influencing personal life.

It is evident that the motivational level of first level managers (grade five) is good. The factors contributing largely to this level of satisfaction include: achievement, recognition, the work itself and 
responsibility as well as the hygiene factor interpersonal relationships. The contribution to satisfaction by motivators (fifty two point three percent) is relatively low for managers. One can expect that motivators will contribute substantially more to satisfaction than hygiene factors (forty seven point seven percent), when managers strive for self-actualisation. Factors that contribute to dissatisfaction are advancement, company policy and procedures, salary, status and job security. Hygiene factors contribute seventy three point nine percent and motivators twenty six point one percent to dissatisfaction. The high level of hygiene- based dissatisfaction and the limited level of motivatorbased satisfaction indicate reason for concern on first level management.

The motivational level for employees (grade six and up) is good and similar factors contribute to good levels as those for first level managers. Other significant factors include interpersonal relationships and supervision. On the other hand factors such as advancement, company policy and procedures, salary, status, job security and factors influencing personal life, are responsible for dissatisfaction. There is a very small difference between first level management and employees regarding the contribution of motivators (fifty two point eight percent) and hygiene factors (forty seven point two percent) to satisfaction. Hygiene factors contributed slightly more for managers (seventy three point nine percent) than for employees (sixty six point eight percent) to levels of dissatisfaction whereas motivators contributed more to dissatisfaction for employees (thirty three point two percent).

The motivational profiles based on hygiene and motivator factors can be summarised as follows in order to indicate the significant differences that exists. Significant differences are further analysed with reference to Switching Engineering region, position within the division, highest qualification, amount of years employed at Telkom, time within a specific division, total salary package, age and gender differences.

Table 1 Significant motivational profile differences

\begin{tabular}{|c|c|c|c|c|c|c|c|c|c|c|c|c|c|c|c|c|c|}
\hline & \multicolumn{6}{|c|}{ Motivator factors } & \multicolumn{11}{|c|}{ Hygiene factors } \\
\hline & 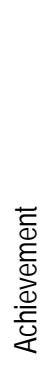 & 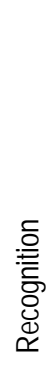 & 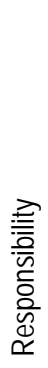 & 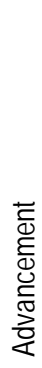 & 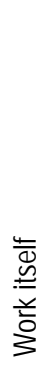 & 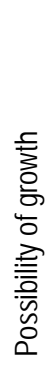 & $\frac{\mathbb{d}}{\underset{\mathbb{d}}{\mathbb{N}}}$ & 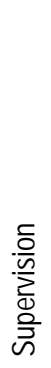 & 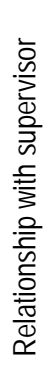 & 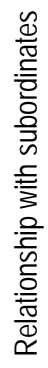 & 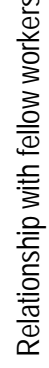 & 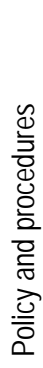 & 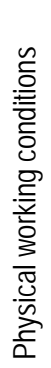 & 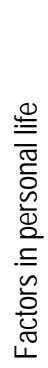 & $\begin{array}{l}\text { 足 } \\
\text { 荧 } \\
\text { ஸ口 }\end{array}$ & 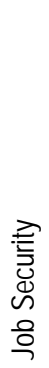 & 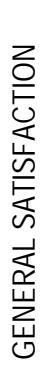 \\
\hline Region & & & & & & & $X$ & & & & & & $x$ & & $x$ & & \\
\hline Position & $x$ & & $X$ & $x$ & & $x$ & $x$ & & & & & $x$ & & $x$ & $x$ & $X$ & $x$ \\
\hline Qualification & & & $x$ & & & & & & & & & & & & & & $x$ \\
\hline Years employed & & & & $x$ & & $\mathrm{X}$ & & & & & & $x$ & & & $x$ & $x$ & \\
\hline Time in division & $X$ & & $x$ & $x$ & & $X$ & $X$ & & & & & $X$ & & & $x$ & $X$ & \\
\hline Total salary & $X$ & & $X$ & & & & & & & & & & & & $X$ & & $x$ \\
\hline Current age & $X$ & & & $x$ & & $x$ & & & & & & $x$ & & & $x$ & $x$ & \\
\hline $\begin{array}{l}\text { Gender } \\
\text { difference }\end{array}$ & & & & & & & & & & & & & & $x$ & $X$ & & \\
\hline
\end{tabular}

Source: Menyennett 1999:96

\section{- Region}

As summarised in Table 1, there are significant differences between the Switching Engineering regions on the hygiene factors: salary, physical working conditions and status. The Western region is the most dissatisfied with salary followed by the North Eastern region. With reference to the hygiene factor, physical working conditions, the North Eastern and Eastern regions are highly dissatisfied with their working conditions, whereas the Gauteng Central region is least dissatisfied. The North Eastern 
region is most dissatisfied with status followed by the Gauteng Central and Western regions. The Central region is least dissatisfied with status.

\section{- Position}

There are significant differences between position or job level and the motivators: achievement, responsibility, advancement and the possibility of growth. There are also significant differences between position and the hygiene factors: salary, policy and procedures, factors in workers' personal life, status and security. There are strong levels of no satisfaction present amongst grade five and grade eight/nine employees compared to other job levels, with reference to achievement. Grade five managers experience the highest level of satisfaction with responsibility, followed by grade six, grade seven, grade eight/nine and grade ten/twelve. There are strong levels of dissatisfaction among grade ten/twelve employees with the motivator: responsibility. Advancement, or rather the lack thereof, is also a strong cause for dissatisfaction among grade eight/nine employees and across the other job levels extremely low. Satisfaction for employees on the grade eight/nine job level differs significantly from other levels when looking at the motivator: the possibility of growth. High levels of dissatisfaction are present. Grade ten/twelve employees indicate strong signs of satisfaction with the possibility of growth.

Grade eight/nine employees followed by grade six employees are very dissatisfied with company's policy and procedures. It is interesting to note that the strongest level of no dissatisfaction with company policy and procedure is present among the grade ten/twelve employees. Factors impacting the workers' personal lives negatively are most prevalent in grade ten/twelve employees followed by grade seven employees. Grade eight/nine employees are extremely concerned about job security leading to dissatisfaction with grade ten/twelve employees being least concerned about job security. When looking at the general level of satisfaction, the highest satisfaction level is prevalent with grade five employees and the least with grade eight/nine employees (Menyennett 1999: 97).

\section{- Qualification}

There are only two significant differences between level of education and the motivator: responsibility and the general level of satisfaction. Employees with matric or less are least satisfied in terms of responsibility.

\section{- Years employed}

There are significant differences between the amount of years employed at Telkom and the motivator factors: advancement and possibility to growth. There are further significant differences between the employment period at Telkom and the hygiene factors: policy and procedures, status and security. The highest level of dissatisfaction for advancement are present in employees that have been employed for more then twenty years at the organisation, not excluding dissatisfaction present among the other categories. Employees that have been employed for more than twenty years are also very dissatisfied with the possibility of growth although strong levels of satisfaction are present amongst employees that have been employed for less than ten years.

\section{- Time in division}

Significant differences exist between the employees' work duration in the Switching Engineering division and the motivator factors: achievement, responsibility, advancement and the possibility of growth. Furthermore there are significant differences between the hygiene factors: salary, policy and procedure, status and security, and time in the mentioned division. Employees that have been in the Switching Engineering division for less than two years are most satisfied in terms of achievement, responsibility and the possibility of growth. There are strong levels of dissatisfaction with the: responsibility of growth; company policy and procedures; and status and job security, for employees that have been in the division for more than five years. This group is most dissatisfied with salary. Those employees in the two to five years group presents dissatisfaction with company policy and procedures. Dissatisfaction is lowest amongst those employees with less than two years service in the division (Menyennett 1999: 98).

\section{- Total salary}

Significant differences also occur between the different groups, categorised according to total salary and the motivators: achievement, responsibility, and the hygiene factor status. Employees earning 
annual salaries in the band R100k to R150k are the most satisfied in terms of achievement followed by those earning more than R150k per annum. Those earning more than R150k are most satisfied in terms of responsibility and most dissatisfied in term of status.

\section{- Age group and gender}

There are statistically significant between age groups and the motivators: achievement, advancement and the possibility of growth, as well as the hygiene factors: company policy and procedure, status and security. Out of the two age groupings, i.e. those under forty and those over forty, employees under the age of forty experience the most satisfaction in terms of achievement, advancement and the possibility of growth. Those over forty indicated dissatisfaction with the possibility of growth and advancement. This group also experienced the most dissatisfaction with company policy and procedure, status and security (Menyennett 1999: 99).

Significant differences exist between males and females regarding the motivators: recognition and responsibility, and the hygiene factors status and factors influencing personal life. Females are most satisfied with recognition and males with responsibility. Males were most dissatisfied with status, while females reported the highest dissatisfaction due to work factors that were influencing their personal life.

\section{RECOMMENDATIONS}

It is important for management not to ignore the factors that contributed to satisfaction. Management should take note of these factors and take the necessary steps to ensure that they persist. In actual fact, management should endeavour to strengthen them as much as possible.

Factors that contributed to dissatisfaction should be addressed. The following factors are strong dissatisfiers:

\section{Company policy and procedure}

The manipulation of this factor is very difficult in the larger organisation. However, many of the problems may pertain specifically to the divisions, and can therefore be manipulated.

It would benefit management to determine which factors is the main source. One factor for example which contributed to strong levels of dissatisfaction and was very prominent in employees that have been in the Switching Engineering division for more than 5 years, is Telkom's affirmative action policy. Dissatisfaction with the affirmative action policy was also very prominent amongst grade eight/nine employees. This policy is being implemented vigorously in Telkom as well as in other companies in South Africa. This factor cannot be eliminated due to the new Labour Relations Act and management should therefore focus on manipulating the process for implementing affirmative action and create unique approaches fitting their organisation (Menyennett 1999: 104).

\section{Advancement}

This factor, which is a motivator, is contributing significantly to dissatisfaction. Employees feel that there are no promotion opportunities in the division. Due to the rigid hierarchical structure in the division and in Telkom, it is very difficult to manipulate this factor. This could be one of the largest contributors to high employee turnover in Telkom. In the over forty age group as well as those employees that have been in Telkom for more than twenty year, this factor appeared very strong. These employees are usually most experienced and may see younger employees as a threat (Menyennett 1999: 104).

However, one must bear in mind that few of these employees in these two categories are really sought after in the broader South African market. Management should guard against these employees becoming negatively motivated and therefore negatively influencing other employees. Grade eight/nine employees in the Switching Engineering division also indicate the highest level of dissatisfaction for advancement. These are the most likely candidates for promotion to the next level 
(grade seven) and management should guard losing these employees to other divisions in the larger corporation.

\section{Salary}

This factor virtually always appears as a strong dissatisfier. It seems that most people are never satisfied with their remuneration. The important thing about hygiene factors is that it has an increasing zero-point. In other words, salary increases only motivate people to seek the next salary increase.

\section{Status}

This factor includes symbols such as office, position title, company car and reserved parking. Status is a perception and although it might not be possible to provide all with most of these physical symbols, it is possible to change the non-tangible factors like position title. Management must focus their efforts on identifying as well as satisfying as many of these perceived status symbols.

\section{Job security}

Job security pertains to issues such as feelings of how secure a person's job is, the future of Telkom, and fringe benefits, for example pension. Based on the research results, it is evident that job security is causing strong dissatisfaction. This hygiene factor is also based on perception. If Telkom wants to become a competitive organisation or may be forced into a more competitive environment, it will need to address this issue. Telkom cannot compete in a potential national as well as international competitive environment, if employees feel that there is neither a future for Telkom, nor personal job security.

One would expect some level of dissatisfaction with job security from older employees, especially those over fifty years of age, since they are very likely candidates for retrenchment if the company restructure. Management must assist employees in establishing a future in order not to loose them to future entrants to this market.

\section{Factors influencing personal life}

The two main subjects examined for this factor were stress and longer working hours. It is important that the employee's work does not severely interfere with his or her personal life since this can quickly lead towards negative feelings toward the job. It is interesting to note that the lowest job level employees, i.e. grade ten/twelve indicate the most dissatisfaction with this hygiene factor. One would rather expect that the first level managers (grade five) would indicate much stronger signs of dissatisfaction with this factor, than the lowest level of employees.

Management can address these issues by limiting overtime to a minimum. Stress affects each person differently. Another good start to addressing this problem would be to send employees, especially grade ten/twelve, on a stress management-training course.

Other factors that contribute to dissatisfaction are the possibility of growth and working conditions. Hygiene factors are vital in the life of the employee, and neglect of these shall trigger feelings of dissatisfaction, lower levels of motivation, thus influencing productivity and profitability. It is therefore vital that hygiene factors be managed properly. As mentioned, it is important for management not to ignore the factors that contributed to satisfaction. Management should take note of these factors and take the necessary steps to ensure that they persist to strengthen them where possible (Menyennett, 1999:106).

The factors that contributed mainly to satisfaction are:

\section{i. Achievement}

A sense of achievement is important in all spheres of life and is usually a measure of success. Attaining set goals or objectives builds strong levels of satisfaction and thus motivation. The need for achievement is one of the strongest driving forces amongst successful entrepreneurs. 
From this study it is evident that this factor leads to higher levels of satisfaction. To maintain this, it is important to ensure that the job always stays challenging. The rapid change of technology in this division will at least always ensure that the work remains challenging in this aspect. Overall the levels of satisfaction due to achievement are generally high

ii. The work itself

It is encouraging to note that most employees are very satisfied with the type of work they do. Managers must still continue make the work content as interesting as possible. This will build strong levels of motivation. Most female respondents also enjoyed the type of work they do.

\section{iii. Interpersonal relationships}

This factor combines the two hygiene factors of relationship with subordinates and relationship with fellow workers. It is evident that there is good support amongst employees, as well as support for supervisors. This has lead to strong team spirit in the divisions. Teamwork is crucial for the success of any company and team efforts must be motivated to address the greater hierarchal limitations of Telkom.

\section{iv. Supervision}

This factor, which is a combination of the hygiene factors supervision and relationship with supervisor, also contributed to strong levels of satisfaction. It is crucial for supervisors to maintain this good working relationship with employees. It is critical for the success of the supervisor but also for the success of the division. It is evident that this good supervisor - employee relationship enhances the team spirit that exists within the division and can build strong levels of satisfaction. This is essential for survival in future demanding environments.

\section{v. Responsibility}

Employees are satisfied with their responsibility in terms of their liability and accountability for the jobs that they perform. In general, this strengthens levels of motivation in the division. Grade five managers and employees earning more than R150 000 per annum, indicate the highest levels of satisfaction due to responsibility. Employees with less than matric education experienced the least satisfaction in terms of responsibility. Continuous learning and development on all levels are therefore essential. Teamwork will allow greater participation and enhance a culture of growth and learning

\section{CONCLUSION}

To conclude, it is important for management to look at enriching jobs on a continuous basis. This is the only way of achieving long-term motivation to ensure job satisfaction. A culture of continuous developing and learning based on team efforts will ensure that not only single divisions but the organisation as a whole be geared for future demands. This future entails a potential highly competitive business environment with vast changes in every possible field. Changes indicate uncertainty, which directly influences motivational levels of employees. In every step organisations take to gear them for the future, they must never forget to find the most suitable route to implement change. The solution is based on informed and positively motivated employees who participate continuously in the change process at all levels. 


\section{BIBLIOGRAPHY}

HELLRIEGEL D \& SLOCUM JW. 1996. Management. $7^{\text {th }}$ ed. Cincinnati : South-Western.

IVANCEVICH JM, LORENZI P, SKINNER SJ \& CROSBY PB. 1994. Management: quality and competitiveness. Burr Ridge : Irwin.

KREITNER R \& KINICKI A. 1989. Organisational behavior. Boston : Irwin.

MENYENNETT C. 1999. Worker motivation in a technical division of Telkom SA. Johannesburg: RAU.

MESCON MH, ALBERT M \& KHEDOURI F. 1988. Management, 3rd ed. New York: Harper \& Row.

TELKOM. 2000a. Background. Internet. http://www.telkom.co.za/company/background/shtml. [Accessed: 24 October 2000]

TELKOM. 2000b. Vision. Internet. http://www.telkom.co.za/company/vision/shtml. [Accessed on 24 October 2000] 